\title{
12. A private institutional investment perspective
}

\author{
David A. McGrory*
}

\subsection{INTRODUCTION}

The other contributors to this book provide some in-depth analysis from a range of perspectives including intellectual property (IP) law, human rights law, competition law and environmental law. They examine the interaction of the various legal specialisms and also the organizations that have attempted to formulate policy responses to some of the relevant issues, including the United Nations Framework Convention on Climate Change (UNFCCC), the World Intellectual Property Organization (WIPO) and the World Trade Organization (WTO). In contrast, this chapter seeks to take a step back from the high level policy and legal theory and focuses instead on the role that private institutional investment can play in the development of climate change technologies. A pragmatic view is taken of the risk/reward nature of private institutional investment and the effect that interference with typical investment funding models could have on the development of scalable climate change technologies. From a private institutional investment perspective, there has to be a concern that implementation of compulsory licensing or enforced sharing of intellectual property rights (IPRs) could result in outcomes that are diametrically opposed to the outcomes that supporters of such policies would seek to achieve.

\subsection{A FUNDING GAP}

Kyoto Protocol targets for reductions in emissions have been consistently missed. The targets are often cited as the measure of what the signatory nations should be aspiring to but these targets need to be set in context. It should be borne in mind that, even if the signatory nations to the Kyoto Protocol were to achieve the targets for reduction of greenhouse gas 
emissions, then all that they would be doing is returning their greenhouse gas emissions to a level only marginally below 1990 levels. No significant reductions will be made. The ultimate goal would be a world economy which emits zero greenhouse gases. This goal is considered so unrealistically ambitious that it is generally accepted that setting targets to reach that goal would be a futile exercise. Given the range of the factors which can have an impact on emissions (such as changes in human practices) and the Kyoto flexibility mechanisms and the opportunities for emissions trading which are discussed by Ghaleigh and by Morgera and Kulovesi in this collection, it is difficult to establish the amount of investment required by signatory nations in order to achieve the Kyoto Protocol targets. In his contribution, Tuncak refers to the International Energy Agency figures of US\$580 billion to US\$1.46 trillion. ${ }^{1}$ Yet the consistent failure to meet targets, particularly on a global scale, ${ }^{2}$ suggests that more action is required at all levels; and as also discussed by Jones in this collection, this will include investment in technology.

The amounts required in future years will also need to increase to offset previous shortfalls. As is considered by Jones and by Tuncak in this collection, the levels of investment necessary cannot be met, and are not presently being obtained, from public sources alone. It is essential that public and private funds are invested together if there is to be any hope of reaching adequate funding levels. In fact, given that the Western economies of the world have gone through a particularly difficult time in recent years, many governments are concentrating on deficit reduction programmes. This only places an even greater emphasis on private sector funds to bridge the funding gap.

Some of the other chapters in this book explore initiatives in the private sector which will help. Big business is certainly taking corporate social responsibility much more seriously now than in the past, but whilst not-for-profit ventures are to be applauded, they simply cannot be implemented on anything like the scale required to make a material impact on the funding shortfall. Similarly, ventures such as the EcoPatent Commons are a positive initiative but a sceptic would argue that any IPRs with real value attached to them will be exploited by their owners and held back from not-for-profit schemes. Notwithstanding the increase in initiatives that have an environmentally friendly goal, the fact remains that the bulk of the funding requirement will need to be met by private sector money being invested in companies with a financial model based on the generation of profit for its stakeholders.

If private sector investors are to play a significant role in bridging the environmental technology funding gap, it is essential that all parties get 
comfortable with the idea that the private sector needs to make a return on its investment. To the extent that no or limited returns are available, investment on the scale required will not materialize.

\subsection{FUNDING OF START-UP AND EARLY STAGE COMPANIES}

Whilst public bodies such as universities, together with large multinational companies, will undoubtedly develop IPRs that will be valuable in combating climate change, the vast majority of development in this field is likely to be concentrated in or have its origins in start-up, early stage or growth companies. This is partly because of the vast numbers of such companies in existence; but also because research projects that start in universities are often spun out into private companies in order to progress them further.

A significant proportion of the IPR development work undertaken in large multinational companies occurs in such companies as a result of the acquisition of smaller businesses. It stands to reason, then, that the funding of start-up, early stage and growth companies is critical to the development of valuable climate change technology IPRs. If companies are to be founded to develop IPRs, nurtured to the point that they can become self-sufficient, and then grow to the point that they generate profits which can partly be utilized for reinvestment to create and develop more IPRs, it is essential that they are supported through the early stages of the funding cycle. This tends to be a period in the financial development of a company where it is too early to generate any profit and often too early to even generate any revenue. Companies that are pre-profit and pre-revenue often face severe funding difficulties and it is useful to understand the funding landscape within which such businesses operate.

Most start-ups receive their initial funding from the founders and this is often supplemented with funds from family and friends. One might take the view that the next port of call for such businesses would be bank-funded debt finance in the form of term loans and overdrafts but it is important to understand that this type of funding is largely unavailable to start-up and early stage companies. There are two principal reasons for the inability of early stage companies to raise debt finance: (1) the inability to provide adequate security coverage; and (2) the inability to service typical debt repayment profiles.

Almost all bank-based finance requires the debt to be covered by security over the company's assets. In early stage and start-up companies, 
there are often no assets that are suitable or sufficient to give adequate coverage to the banks. Such businesses rarely own any material tangible assets and their main business assets often consist of the people employed in the business and any IPR owned by the business. Assets of this kind do not provide the kind of security coverage that banks require.

Even if a company is able to provide meaningful security coverage for a bank, another key factor in any lending decision will be the bank's assessment of the borrower's ability to meet its scheduled repayment obligations. Any company that is generating low or patchy cash flow will have great difficulty in persuading a bank that it can meet such obligations.

For these and other reasons, bank funding tends not to be a realistic option for early stage companies. This is the case even in a positive market for lending and the difficulties have been exacerbated in the risk-averse lending environment post-2008 where banks remain heavily focused on repairing their balance sheets.

Another common source of corporate finance is the public capital markets. Again, this is an avenue of finance that is largely closed off to early stage companies. The primary reasons for this are that they are unlikely to have marketable securities and equally unlikely to be in a position to afford either an initial public offering, or service the costs of complying with the regulatory regime imposed on publicly listed companies.

In the absence of some of the more traditional methods of funding, early stage companies tend to seek funding from government bodies through grants and university awards. In addition, it is common to secure funding from trade investors by allowing the company to be acquired by a larger company, thereby creating a parent company that has an interest in ensuring that its subsidiary has adequate access to capital.

The other major source of funding is capital provided by private institutional investors, often referred to as private equity or venture capital houses. In the United Kingdom, venture capitalists tend to focus on investment levels of less than $£ 10,000,000$ which covers the funding requirements of most start-up and early stage companies. Private equity houses tend to focus on larger deal sizes for more mature investee companies.

Venture capital (VC) has a major advantage over debt funding in that it is risk capital, meaning that the return to the investor is based on the success of the company and the valuation attributable to the investor's stake in the company. VC money tends to be committed until a suitable exit event arises, unlike debt finance, where the investment is likely to be repaid by way of regular scheduled repayments. In addition, security 
coverage is not a priority for venture capitalists (VCs). For this and other reasons, VC funding is well-suited to early stage companies that may only have IPRs and staff as assets.

\subsection{IPR AS A 'HIGH BARRIER TO ENTRY'}

Each VC investor will have a different investment strategy and different drivers, both in terms of the type of businesses it is interested in backing and the profile of return that it might expect. Notwithstanding the variety of different approaches across the VC industry, a number of common themes emerge when investors assess funding propositions. These can be summarized as follows:

(a) potential for high, rapid growth;

(b) experienced and ambitious management team;

(c) valuable products/service in expanding market;

(d) high barriers to entry for competitors; and

(e) high likelihood of venture capitalist achieving a good exit.

This book is not the place to go into any detail on the themes listed above, but item (d) is particularly relevant in the context of the themes discussed in this collection. It is important to understand what is meant by the phrase 'high barriers to entry' within the VC community, because it does not have the same negative implications that it would in the context of, e.g., competition law. In a VC context, an investment proposition will be made considerably more attractive where analysis of the market shows that there are high barriers to third party entrants. Where VCs back a company, they want to see that business expand rapidly in order to meet the market demand for its particular service or product. Any market competitors will have a detrimental effect on an investee company's turnover and therefore profit. As a result, VCs are very careful in selecting businesses where it is particularly difficult for others to compete effectively.

There are a number of ways in which the investment criterion of 'high barriers to entry' can be satisfied. It may be that significant investment in terms of time and cash is required in a design or manufacturing process such that any competitor will be a number of years behind an investee company. Equally, it could be the case that the founders and/or management team of the company command such a position of pre-eminence in their field that, as long as their services are secured, the possibility for competitors to access the market is remote. 
Perhaps the most obvious and common example of a high barrier to entry, and certainly the most relevant to the current discussion, is where a business has protected IPRs. In such circumstances, potential competitors can be effectively barred from capitalizing on the technology because to do so could result in an infringement action. Alternatively, potential competitors may be forced to enter into an assignment or licensing arrangement which can generate profits for the investee business. The IPRs of a technology business will often be so crucial to the underlying value of that business that $\mathrm{VC}$ investors will spend a significant amount of time in the due diligence process ensuring that IPR protection is in place.

\subsection{ENFORCED SHARING OR COMPULSORY LICENSING OF IPRS COULD INHIBIT RATHER THAN ENCOURAGE THE DEVELOPMENT OF CLIMATE CHANGE TECHNOLOGIES}

In many cases, besides a strong technical/management team, IPR is the only asset that a start-up or early stage business has, and it therefore forms the basis of the pre-investment value and the post-investment potential value of the business. The value of an IPR asset could be undermined by a competitor developing superior technology, but equally it could be undermined if the company is prevented from protecting an IPR and having an exclusive right to exploit that IPR. Anything which undermines the value of an IPR asset may result in VCs taking the view that the business is not an investable proposition. Given the difficulties of raising finance described above, $\mathrm{VC}$ investment may be the only viable funding source for a company. Businesses frequently fail because they are starved of cash, and when the company is lost, the potential for innovation can be lost too.

It has to be a concern that, if businesses that drive innovation in the economy are starved of funding, they will not generate the advances in climate change technology that are required to solve the world's climate change challenges. If valuable IPR is not generated and developed in these businesses, then the question of how it might be shared with others, either through enforced licensing or otherwise, becomes a moot point. It is vital, therefore, that if the generation of climate change technology is not to be choked off at source, early stage companies must be in a position to attract adequate investment to fund their innovative development work. In order to commit funds, investors need to be confident that 
they will be able to generate sufficient returns, and in order to generate those returns it is essential for technology companies to be able to protect and therefore exploit their IPRs.

In summary, whilst at a policy level, it may seem that the common good would be served by widely disseminating the rights to exploit innovative climate change technologies, the realities of the commercial world are such that investors will quickly switch from an unprofitable asset class to one where they can make an attractive return. The consequences of removing private institutional investment from the funding landscape would be that the already significant funding gap would become wider. If that were to happen, the innovation that is so desperately required to solve the challenges of climate change through technological advancement could not take place and policies that might be designed to improve access to emissions-reducing technology could have the polar opposite effect.

\section{NOTES}

* The views expressed in this chapter are exclusively those of the author and do not necessarily reflect those of Maclay Murray \& Spens LLP.

1. See Chapter 9.

2. See e.g., Department of Energy and Climate Change, 'Progress against emissions targets', available at www.decc.gov.uk/en/content/cms/statistics/climate_stats/gg emissions/targets/targets.aspx. Cf. Kyoto Protocol, available at http://unfccc.int/kyoto_ protocol/items/2830.php. 
David A. McGrory - 9780857934185 Downloaded from PubFactory at $04 / 26 / 2023$ 02:26:42AM via free access 